\title{
PAULO FREIRE HOY, ANTE LA INTENCIONALIDAD DECOLONIAL DEL PENSAMIENTO DEL SUR
}

\section{PAULO FREIRE HOJE, DIANTE DA INTENCIONALIDADE DECOLONIAL DO PENSAMENTO DO SUL}

\author{
Milagros Elena Rodríguez ${ }^{1}$
}

\begin{abstract}
RESUMEN: Volvemos a Paulo Freire: un cántaro que no se agota, con una sabiduría de amor por la vida, con profunda fe en los educandos, un investigador-educador hecho praxis en el centro contaminado de la indignidad humana. En está indagación se trata inmiscuirnos compleja y transdisciplinarmente en la decolonialidad planetaria; con el transmétodo la deconstrucción rizomática transcompleja se cumple con el objetivo complejo de analizar la vida y obra de Paulo Freire como un decolonial planetario adelantado en su tiempo; que da actualmente cátedra de liberación en tiempo de soslayación. Se ubica la indagación en la línea titulada: transepistemologías de los conocimientos-saberes y transmetodologías transcomplejas. En la reconstrucción de la indagación en vía de la deconstrucción, luego de un relato de la realidad venezolana breve; pero con un clamor; Paulo Freire a los 100 años de su vida hecha praxis de la liberación, nos recuerda los valores más esenciales a parte de la libertad, que debemos recobrar como personas; es digno de buscar todo lo que esté a nuestro alcance para lograrlo; expresa el pedagogo. Desmitifica Paulo Freire la imposición del conocimiento para soslayar a cambio de un conocimiento liberador como praxis de la búsqueda de soluciones a las necesidades más apremiantes de la vida de los oprimidos. De esa realidad debemos imprimirnos como misión de vida.
\end{abstract}

PALABRAS-CLAVE: Paulo Freire. Decolonialidad. Praxis.

RESUMO: Voltemos a Paulo Freire: um jarro que nunca se esgota, com uma sabedoria de amor à vida, com uma fé profunda nos alunos, um educador-investigador praticado no contaminado centro da indignidade humana. Nesta investigação, procuramos interferir de forma complexa e transdisciplinar na descolonialidade planetária; Com o transmétodo, a desconstrução rizomática transcomplexa, cumpre o complexo objetivo de analisar a vida e a obra de Paulo Freire como um decolonial planetário à frente de seu tempo; que atualmente está ensinando a libertação em tempos de evasão. A investigação situa-se na linha intitulada: transepistemologias do conhecimento-conhecimento e transmetodologias transcomplexas. Na reconstrução da investigação a caminho da desconstrução, depois de um breve relato da realidade venezuelana; mas com um clamor; Paulo Freire aos 100 anos de vida fez práxis de libertação, lembra-nos os valores mais essenciais para além da liberdade, que devemos recuperar como povo; Vale a pena buscar tudo o que estiver ao nosso alcance para alcançá-lo; expressa o pedagogo. Paulo Freire desmistifica a imposição do saber para evitar em troca de um saber libertador como práxis da busca de soluções para as necessidades mais prementes da vida dos oprimidos. Dessa realidade devemos nos imprimir como missão de vida.

PALAVRAS-CHAVE: Paulo Freire. Decolonialidade. Práxis.

\footnotetext{
${ }_{1}$ Universidad de Oriente, Venezuela. E-mail: melenamate@hotmail.com

(D) http://orcid.org/0000-0002-0311-1705

- Informações completas da obra no final do artigo
} 


\section{ENSIN@UFMS 2021}

ISSN 2525-7056

\section{Rizoma transmetódico: la investigación transcompleja como insurgencia}

Paulo Freire; el liberador en las favelas; el hombre que hizo de su vida una praxis en los oprimidos cumpliría cien (100) años de su nacimiento, el educador brasileño nació el 19 de septiembre de 1921 en Recife, Pernambuco el nordeste brasilero, donde vivió una niñez y juventud signada por la premura económica y el contacto con campesinos, y trabajadores de esta región de Brasil. Es Paulo Freire el ser sensible que padeció las calles del hambre, la cárcel y el exilio; dejando un legado inmenso que debemos heredar y hacer nuestro como praxis de amor; queremos clarificar: ¿qué es el amor para Paulo Freire?; "el amor es un acto de valor, no de miedo, el amor es un compromiso con los demás. No importa dónde los oprimidos se encuentran, el acto de amor es el compromiso con su causa, la causa de la liberación" (FREIRE, 1970, p.70).

De su obra y legado hablaremos prontamente; pero es imperativo comprender sus palabras con mayúsculas dignas de recobrar en el día a día, como la tetra: LIBERACIÓNAMOR-EDUCACIÓN que fue hecha praxis por el último pedagogo del Sur; y que Pedagogía del oprimido es su obra más estudiada, la escribió en Chile cuando estaba desterrado por el gobierno militar del Brasil, publicada en México en 1968, y luego en idioma portugués en 1970, con prólogo de Hernán Fiori; editada en español y en inglés; además en varias versiones como: alemán, italiano, francés, holandés, japonés, sueco, noruego, finlandés, danés, flamenco, griego, árabe, chino; en total más de veintiocho (28) idiomas. ¿Qué es la praxis que hizo de Paulo Freire su obra hecha vida en las calles de los desprotegidos? En el desarrollo de la investigación iremos develando tal interrogante.

La presente investigación transcompleja emerge como insurgencia con Paulo Freire; se trata de ir más allá de las indagaciones tradicionales modernistas-postmodernistascoloniales; para inmiscuirnos en una indagación compleja y transdisciplinar; que con el transmétodo la deconstrucción rizomática transcompleja se cumpla con el objetivo complejo de analizar la vida y obra de Paulo Freire como un decolonial planetario adelantado en su tiempo; que da actualmente cátedra de liberación en tiempo de soslayación.

Se ubica la indagación en la línea titulada: transepistemologías de los conocimientossaberes y transmetodologías transcomplejas. Nótese la convergencia liberación Freiriana decolonialidad planetaria que más adelante fungiremos de interlocutores para analizar esa diada que parece evidente en tanto las dos categorías son portadoras de liberación; y no hay liberación bajo colonialismo o colonialidad. Y que adelantamos es esa una de los nudos 
áridos al momento de analizar el legado de Paulo Freire: la colonialidad bajo la cual se pretende comprender un clamor, un grito de libertad de los oprimidos.

La investigación transcompleja ha corrido el riesgo de ser mal interpretada por personas ortodoxas, rígidas, lineales, coloniales; portadoras de lo anti-liberador; que defienden su parcela del conocer como objeto de poder. No es un credo, ni una ideología, ni una moda; tampoco un nuevo paradigma, por el contrario va fuera de estos, de allí la palabra trans que significa más allá. Dicha indagación, así como acá y las que recorren la bandera liberadora de la forma de conocer; sienta las bases de un nuevo episteme, que denomino transepisteme, orientado hacia el renacer de la conciencia del ser humano: un saber ecosófico; que sin duda es liberador y ateniente al respeto por la condición humana; que desde el proyecto transmodernista tiene su asidero decolonial planetario (Rodríguez, 2020a).

En la transmodernidad donde nacen los transmétodos, bajo el transparadigma transcomplejo, que son "multimétodos que parten de los métodos existentes y por existir, de la integración de estos métodos y de la resultante, que estará más allá de los mismos" (RODRÍGUEZ, 2020a, p.4). ¿Cómo nacen los transmétodos? Ya se conoce la escaza destreza, disposición y amplitud del pensamiento disciplinar para entender las múltiples realidades del mundo complejo. De tal manera, que investigar en la transmodernidad, no puede ser sólo bajo el pensamiento disciplinar; se ha de complejizar; se ha de conformar un pensamiento complejo y transdisciplinar con transmétodos inéditos de la autora de la investigación (RODRíGUEZ, 2020b). Los transmétodos nacen en el acto indisciplinar de las investigaciones modernistas.

Con la presente investigación queremos deconstruir y reformar desde la obra de Paulo Freire y develar la crisis antilibertaria en el Sur, que claman por un reconstrucción a la luz del legado del gran educador del planeta tierra; si del planeta; pues su legado comienza en Brasil; pero no hay lugar donde no se necesite estudiar y legar sus obras a los oprimidos; lo temido por los colonizadores que niegan la razón de ser y existir al que para ellos no tiene la talla de ser humano que puede aportar a la humanidad; estos son los ejes de poder siempre tiene una anti-fe para con la franja que ellos mismos construyeron de miseria y desolación: negados de la historia por no pertenecer a los privilegiados de mundo.

La deconstrucción como transmétodo es rizomática; y de allí los nombres anti tradicionalistas a la denominadas investigaciones denotadas por: introducción, desarrollo, 
resultados y conclusiones; sino que va más allá a complejizar en estructuras que no intentan buscar verdades acabas; sino para construir trans-epistemes, más allá del conocimiento tradicional, "se trata de una anti-genealogía que rompe con las estructuras estáticas divisorias de presentar las indagaciones en las que las partes se dividen indisolublemente en un ir si un venir" (RODRÍGUEZ, 2019, p.4). Así estaremos culminando y al mismo tiempo regresaremos con incisiva fuerza a volver sobre la crisis en el Sur y nuevamente algunos aportes de Paulo Freire a la decolonialidad planetaria. Es de resaltar la liberación del sujeto investigador desde dicho transmétodos; así las subjetividades están presentes directamente de primera voz; al ardor del sentir y admiración por el legado de Paulo Freire y el reconocimiento de las necesidades actuales de la praxis.

Como civilización del Sur, especialmente, que adopta en paso a la descolonización donde se rescata lo olvidado o soterrado en la modernidad, "la Transmodernidad es un nuevo proyecto de liberación de las víctimas de la Modernidad, la "otra-cara" oculta y negada" (DUSSEL, 1992, p.62). Y esa liberación es parte de la lucha de Paulo Freire; pues no hay liberación sin decolonialidad; así la deconstrucción rizomática como transmétodo; va a deconstruir las relaciones jerárquicas del poder, para la liberación de la hegemonía y "la reconstrucción de una sociedad política fundamentada en la solidaridad social, la antropoética, el amor por la tierra; la condición humana. Desde este sentido, deconstruir es también, descolonizar" (RODRÍGUEZ, 2019, p.8). Para luego, reconstruir a la luz de la obra y vida Freiriana.

En lo que sigue vamos a revisar algunos aspectos fundamentales de la obra de Paulo Freire; incidiendo siempre en la crisis del Sur lo que falta por hacer; lo que la educación colonial aún ha impedido de la liberación; y la necesaria liberación onto-epistemológica del saber para ir a un transepisteme urgente en estos tiempos. Se declara que se cumple con el objetivo complejo de la indagación; pero que es insuficiente la revisión de las obras freirianas; son un cántaro que no se agota; en tanto el análisis a la luz de las mentes decolonizadas; se invita al lector a advertir la subjetividad de la autora que le da el transmétodo en tanto la transmodernidad como proyecto decolonial le invita a una mirada profunda desde las obras freiriana a la luz de las necesidades de la educación hoy.

En lo que sigue se presenta un gráfico que intenta resumir el presente rizoma. 
Figura 1. La investigación transcompleja como insurgencia

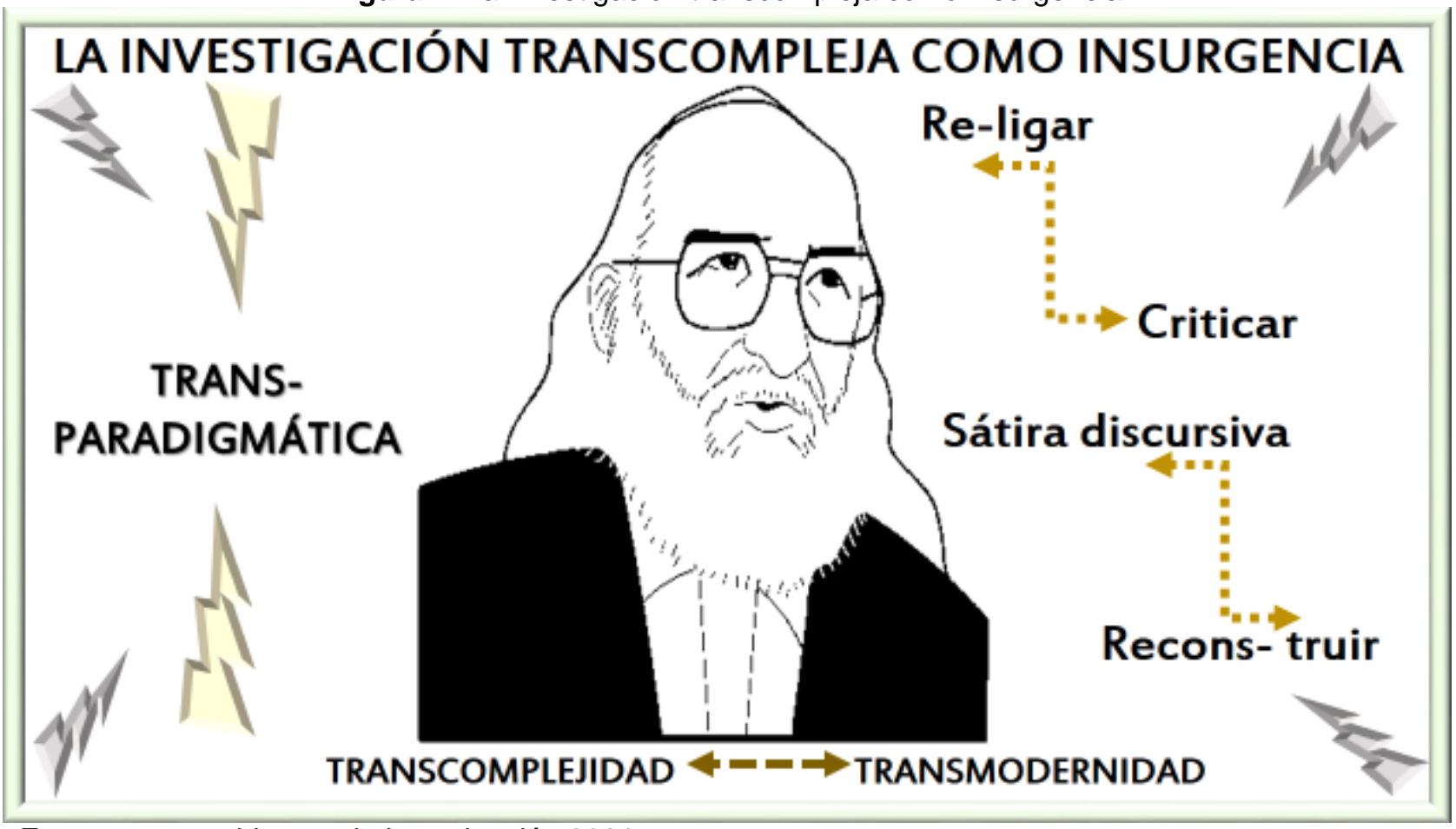

Fuente: construida para la investigación 2021.

En lo que sigue, vamos de manera rizomática entramando las ideas freiriana a la luz de la transcomplejidad.

\section{Rizoma Freiriano: Paulo Freire un legado que no debe morir}

En cuanto a la productividad intelectual de Paulo Freire es inmensa en variedad y creación las obras de éste gran pedagogo; podemos resumir algunas obras, con riesgo a exclusión; por ello afirmamos que la revisión no es exhaustiva tenemos: 1959: Educação e atualidade brasileira. Recife: Universidad Federal de Recife, 139p. (Tesis de concurso público para la cátedra de Historia y Filosofía de la Educación de Bellas Artes de Pernambuco), 1961: A propósito de uma administração. Recife: Imprensa Universitári, 1963: Alfabetização e conscientização. Porto Alegre: Editora Emma.

Un segundo momento: 1967: Educação como prática da liberdade. Introducción de Francisco C. Weffort. Río de Janeiro: Paz e Terra, 1968: Educação e conscientização: extencionismo rural. Cuernavaca (México): CIDOC/Cuaderno 25, 1970: Pedagogia do oprimido. Publicado con prefacio de Ernani Maria Fiori. Río de Janeiro, Paz e Terra, 1971: ¿Extensão ou comunicação? Río de Janeiro: Paz e Terra, 1976: Ação cultural para a liberdade e outros escritos. Traducción de Claudia Schilling, Buenos Aires: Tierra Nueva, 
1977: Cartas à Guiné-Bissau. Registros de uma experiência em processo. Río de Janeiro: Paz e Terra, 1978: Os cristãos e a libertação dos oprimidos. Lisboa: Edições BASE, 1979: Consciência e história: a práxis educativa de Paulo Freire (antología). São Paulo: Loyola, 1979: Multinacionais e trabalhadores no Brasil. São Paulo: Brasiliense.

Entre otras: 1980: Quatro cartas aos animadores e às animadoras culturais. Ministério da Educação e Desportos, Santo Tomé y Príncipe, 1980: Conscientização: teoria e prática da libertação; uma introdução ao pensamento de Paulo Freire. São Paulo: Moraes, 1981: Ideologia e educação: reflexões sobre a não neutralidade da educação. Río de Janeiro: Paz e Terra, 1981: Educação e mudança. Río de Janeiro: Paz e Terra, 1982: A importância do ato de ler (em três artigos que se completam). Prefacio de Antonio Joaquim Severino, 1982: Sobre educación (Diálogos), Vol. 1. Río de Janeiro: Paz e Terra, 1982: Educação popular. Lins (SP): Todos Irmãos, 1983: Cultura popular, educação popular.

Un tercer momento: 1985: Por uma pedagogia da pregunta, 1986: Fazer escola conhecendo a vida, 1987: Aprendendo com a própria história. Río de Janeiro: Paz e Terra, 1988: Na escola que fazemos: uma reflexão interdisciplinar em educação popular, 1989: Que fazer: teoria e prática em educação popular, 1990: Conversando com educadores. Montevideo: Roca Viva, 1990: Alfabetização - Leitura do mundo, leitura da palavra. Río de Janeiro: Paz e Terra, 1991: A educação na cidade. São Paulo: Cortez, 1992: Pedagogia da esperança: um reencontro com a Pedagogia do oprimido. Río de Janeiro: Paz e Terra, 1993: Professora sim, tia não: cartas a quem ousa ensinar. São Paulo: Olho d'água.

Un cuarto momento: 1993: Política e educação: ensaios. São Paulo: Cortez, 1994: Cartas a Cristina. Prefacio de Adriano S. Nogueira; notas de Ana Maria Araújo Freire. São Paulo: Paz e Terra, 1994: Essa escola chamada vida. São Paulo: Ática, 1985; 8a edição, 1995: À sombra desta mangueira. São Paulo: Olho d'água, 1995: Pedagogía: diálogo e conflito. São Paulo: Editora Cortez, 1996: Medo e ousadia. Prefacio de Ana Maria Saul; Río de Janeiro: Paz e Terra, 1987, 1996: Pedagogía da Autonomia. Río de Janeiro: Paz e Terra, 2000: Pedagogía da indignação - cartas pedagógicas e outros escritos. São Paulo: UNESP.

El investigador de la pedagogía critica: Henry Giroux en especial hace una subsisto y a la vez amplio resumen en Giroux (1998) en un artículo titulado: Una vida de lucha, compromiso y esperanza; en donde afirma que: 
El genio de Freire consistió en elaborar una teoría del cambio y el compromiso sociales que no era vanguardista ni populista. Aunque tenía una profunda fe en la capacidad de las personas corrientes para configurar la historia y convertirse en agentes críticos creadores de sus propios destinos, se negó a dar un sesgo romántico a la cultura y a las experiencias producidas por las condiciones sociales opresivas (GIROUX, 1998, p.44).

Henry Giroux reconoce el genio de Paulo Freire, el hombre que padeció y vivenció los problemas de su época, la cárcel, el destierro de su tierra y presenció la dicha de la liberación de su gente. Un ser humano que con su método de alfabetización libera de la opresión a los oprimidos y opresores con una clave principal: el diálogo desde el amor, la humanización y la educación problematizadora.

Queremos rescatar esencias en la Pedagogía del Oprimido, la obra más conocida de Freire, como ya lo dijimos. De dicha obra nos preguntamos: ¿podríamos describir y analizar la relación dialéctica opresor-oprimido, planteada por Paulo Freire en la Pedagogía del Oprimido? Freire señala las faltas en el sistema tradicional de educación y cómo sirve a los opresores. De donde "el educador aparece como su agente indiscutible, como su sujeto real, cuya tarea indeclinable es 'llenar' a los educandos con los contenidos de su narración" (FREIRE, 1970, p.71). Es por ello, que mientras más se inyecte en las mentes pasivas de los educandos más exitosos se sentirán los opresores; y ello sirve luego como caldo de cultivo para oprimir personas y hasta países enteros, luego del amaestramiento.

Es por ello, que Freire ya va clasificando este sistema educativo como una concepción bancaria, al respecto señala el pedagogo que "cuando más vaya llenando los recipientes con sus "depósitos”, tanto mejor educador será (FREIRE, 1970, p. 72). Cuanto más se dejen llenar dócilmente, tanto mejor educandos serán”. A esta opresión que aceptan pasivamente los educandos a la que convoca a que deben liberarse, pues son los oprimidos los que conocen y sufren su realidad.

Los estudiantes en tal sistema pedagógico son tan pasivos, donde "el único margen de acción que se ofrece" a ellos "es el de recibir los depósitos, guardarlos y archivarlos" (FREIRE, 1970, p.72). Más aún, el único que sabe en esta relación opresor-oprimido es el docente, declarado "el dueño exclusivo de la información que será "depositada", el educador siempre va a ser "él que sabe, en tanto los educandos serán siempre los que no saben"” (FREIRE, 1970, p.73). Rezagos serios de esta educación bancaria existen aún en nuestro sistema educativo venezolano; que más adelante se hará eco un grito de auxilio ante opresiones. 
En la relación: opresores-oprimidos, los opresores consideran que sólo ellos son personas, los otros son cosas, seres inútiles, y como tal son tratados como objetos. Los opresores tienen una conciencia opresora que transforma todo aquello que le es cercano en objeto de su dominio. Ésta tendencia a inanimar todo y a todos, tiene su base en el empeño de posesión. El dominio completo sobre otra persona, es una tendencia del sadismo; cuyo fin es convertir a la persona en objeto.

Nos preguntamos: ¿Qué pasa con los oprimidos, porque no intentan liberarse? Los oprimidos no alcanzan a ver que alojan al opresor dentro de sí. Hay una autodesvalorización y ejercen un tipo de violencia horizontal. El dilema que tienen los oprimidos es, seguir las prescripciones o tener opciones. Los oprimidos se siente entonces claramente desmejorados y creyentes de que en verdad son inferiores; concepción reforzada siempre por la educación bancaria.

Claramente mayor satisfacción sienten los opresores cuando los oprimidos dejan y aceptan el deposito. Desde luego el opresor siente un fracaso cuando el oprimido se revele y no acepte pasivamente dicho depósito. Tal opinión parece fría, pero en realidad con lo que ocurre es que la educación bancaria "sólo puede interesar a los opresores que estarán tanto más tranquilos cuanto más adecuados sean los hombres al mundo. Y tanto más preocupados cuanto más cuestionen los hombres el mundo" (FREIRE, 1970, p. 79).

Con todo esto es entendible que los dominadores u opresores se ven en la obligación justa para ellos conveniente en sus mentes es el de dificultar al máximo el pensamiento auténtico de sus opresores. Desde luego, Freire piensa entonces y lo manifiesta que estos opresores también están enfermos. La intención ahora es ir más allá a la liberación de la opresión. A la que la pregunta hace referencia.

La liberación no puede resultar de una educación bancaria según Freire, no se puede liberar el oprimido bajo la misma educación opresora. Por ello, el pedagogo en homenaje opina que "la liberación auténtica es la humanización en el proceso" (FREIRE, 1970, p.84), esta humanización ya no se deposita, no es impuesta es liberadora. Hay que tomar conciencia que al oprimido se le ha subestimado, no se ha creído que el piense valiosamente, que el invente, que él pueda resurgir; se rechaza cualquier cuestión importante que desde sus mentes pueda surgir.

Ahora, ¿de qué trata el método de la liberación de Freire? En el método propuesto por Freire, el educador se transforma en educador-educando y los educandos en educando- 
educador. En esta nueva dinámica, los educandos son agentes activos en el proceso educativo y, al superar sus estados pasivos, ya no son herramientas que sirven a los opresores. Así, "éstos, en vez de ser dóciles receptores de los depósitos, se transforman ahora en investigadores críticos en diálogo con el educador, quien a su vez es también un investigador crítico" (FREIRE, 1970, p. 87). Paulo Freire denomina ahora a este tipo de educación una educación problematizadora que exige la reflexión y que "implica un acto permanente de descubrimiento de la realidad" (FREIRE, 1970, p.88).

La educación problematizadora que sólo se da desde una la pedagogía problematizadora "se empeña en la desmitificación" (...) la educación bancaria niega el diálogo en tanto que la educación problematizadora tiene en él la relación indispensable con el acto cognoscente, descubridor de la realidad" (FREIRE, 1970, p.91). Claramente se trata de un cambio radical, de una liberación; es por ello que el pedagogo enfatiza que esta transformación educativa no tiene sentido si los oprimidos quieren meramente asumir el puesto ocupado previamente por sus dominadores "este movimiento de búsqueda sólo se justifica en la medida en que se dirige al ser más, a la humanización de los hombres" (FREIRE, 1970, p.94). Nunca es un trabajo que se puede hacer de una manera individualista.

El oprimido debe estar consciente que la liberación no es fácil, "es un parto. Es un parto doloroso. El hombre que nace de él es un hombre nuevo, hombre que solo es viable en la y por la superación de la contradicción opresores-oprimidos que, en última instancia, es la liberación de todos" (Freire, 1970, p.96). La contradicción opresor-oprimido puede superarse si hay un cambio de percepción del mundo opresor, si hay una expulsión de los mitos creados y desarrollados en la estructura opresora y si hay una transformación de la situación concreta que genera la opresión. Pero bajo la concepción y conciencia práctica en una educación problematizadora; mientras más investigo, me re-ligo al pensar de la colectividad con él, más nos educamos juntos; "cuanto más nos educamos, tanto más continuamos investigando. Educación e investigación temática, en la concepción problematizadora de la educación, se tornan momento de un mismo proceso" (FREIRE, 1970, p.94).

Particularizando nuestra realidad, nada lejana de las crisis estudiadas por Paulo Freire, la crisis colonial soslayadadora de Venezuela urge en estos momentos de la praxis libertaria de Paulo Freire, que llena de vergüenza su ocurrir ya al cumplirse en el año 2021, 
cien (100) años del nacimiento del ser humano que llevo las luchas por la pobreza y la dignidad humana; en lo que sigue se develan deconstruyendo algunas características en los actuales momentos de crisis en todo sentido en Venezuela, la crisis educativa, económica, de valores, del ciudadano, la crisis politiquera. $\mathrm{Y}$ el emerger con la crisis de condiciones que coadyuvan a la crisis de formación con claro propósito alienante que develan las carencias que padecemos.

Aunado a la crisis de migración de actores de las universidades en general; sin menoscabar el saqueo y destrucción de las instalaciones de los recintos universitarios; aunado a la inflación con salarios ínfimos que llevan a docente universitarios a emigrar, trabajar informalmente en mercados mientras su salud peligra con un seguro social que no asegura ningún aspecto de la salud (RODRÍGUEZ; VELÁSQUEZ, 2020). La opresión que narró y vivió en Brasil Paulo Freire esta acá en uno de los países más millonarios en recursos naturales del planeta, las personas disputándose la basura en la calle está en pleno apogeo, las largas colas para recibir dinero efectivo en los bancos de manera indigna, así es nuestra Venezuela.

Quien le escribe sujeto en primera voz, con sus subjetividades es víctima del proceso que describe y declara que no está de acuerdo con violaciones al derecho constitucional, bloqueos, sanciones, invasiones del Norte y muchos menos con golpes de estado en Venezuela, ni en ningún país; la autora no lidera partidos políticos ni polarizaciones estériles que tanto daño han hecho; más ahora en tiempos de pandemia. La autora es una de las profesionales activas en la investigación que ha colaborado junto a excelentes profesionales en la construcción del hacer universitario de este país; vive y padece en Venezuela, le puede hablar con propiedad de como las universidades han sido excluidas, destrozadas y llevadas a su mínima expresión; mientras que en otras casas de estudios las autoridades universitarias permanecen inexistente viendo de lejos la destrucción; el pueblo ha sido indolente en defender la universidad donde se educaron sus hijos y el provenir queda a céfalo y de esa manera sigue la ruina del país, que es la catástrofe de sus universidades, de su Educación Universitaria (LEMUS; VELÁSQUEZ; RODRíGUEZ, 2020).

Recientemente, de la Universidad de Oriente, ubicada en el Oriente venezolano, cubriendo cinco (5) estados, con cinco (5) núcleos y varias extensiones ha sido saqueada, el epistemicidio ha llegado a sus bibliotecas quemadas; situación que ocurre en países en guerra; aquí ha ocurrido donde supuestamente no hay guerra; yo digo que sí; estamos en 
la guerra por ver quien aporta más a la destrucción del país. Los profesionales vivimos la guerra de nuestros salarios a la mínima expresión salarian, en menos de 20 dólares un docente Postdoctora a dedicación exclusiva, además de la erradicación de nuestras jubilaciones. Somos indefensos ante un estado opresor que nos ha denigrado como profesionales de alto nivel en nuestro propio país, lo que ha causado una migración, huida para sobrevivir de alto nivel.

En la indagación titulada: Rasgadas las vestiduras en la Universidad de Oriente República Bolivariana de Venezuela (LEMUS; VELÁSQUEZ; RODRíGUEZ, 2020) Udistas con gallardía, sembradores de amor en su recinto sus medallas en nuestro pecho, llevamos "en nuestro sentir la necesidad de ser atendidos por la comunidad nacional e internacional; a los que verdaderamente hace políticas educativas; a los que les duele Venezuela, su gente y han gozado de sus frutos" (LEMUS; VELÁSQUEZ; RODRíGUEZ, 2020, p.26). Como pueden ver Ustedes estimados lectores el dolor aflora ante la destrucción de las universidades de Venezuela y con ello la Universidad de Oriente; saqueada la Universidad Central de Venezuela, patrimonio cultural de la humanidad; entre tantas otras.

En la crisis que atesoramos, en las necesidades de volver con gallardía a la liberación freiriana hay mucho que decir; más para efectos de la deconstrucción por ahora es suficiente; entendiéndose que seguimos en los rizomas que viene inmiscuyéndonos en el asunto. Nota el lector que los rizomas como títulos son sólo una formalidad; en realidad la complejidad del discurso no desune las ideas y como en la Biología el árbol va a la raíz pasa por el tallo; regresa a los frutos y esa conectividad regresa a la raíz. Así como tal es el discurso.

En lo que sigue se presenta en gráfico el proceso de opresión liberación de Paulo Freire un legado que no debe morir; este proceso de liberación ha sido analizado por diversos autores a la luz de las obras freirianas; pero que la realidad es que el proceso de opresión se continua repitiendo. 


\section{ENSIN@UFMS 2021}

ISSN 2525-7056

Figura 2. Proceso freiriano de liberación

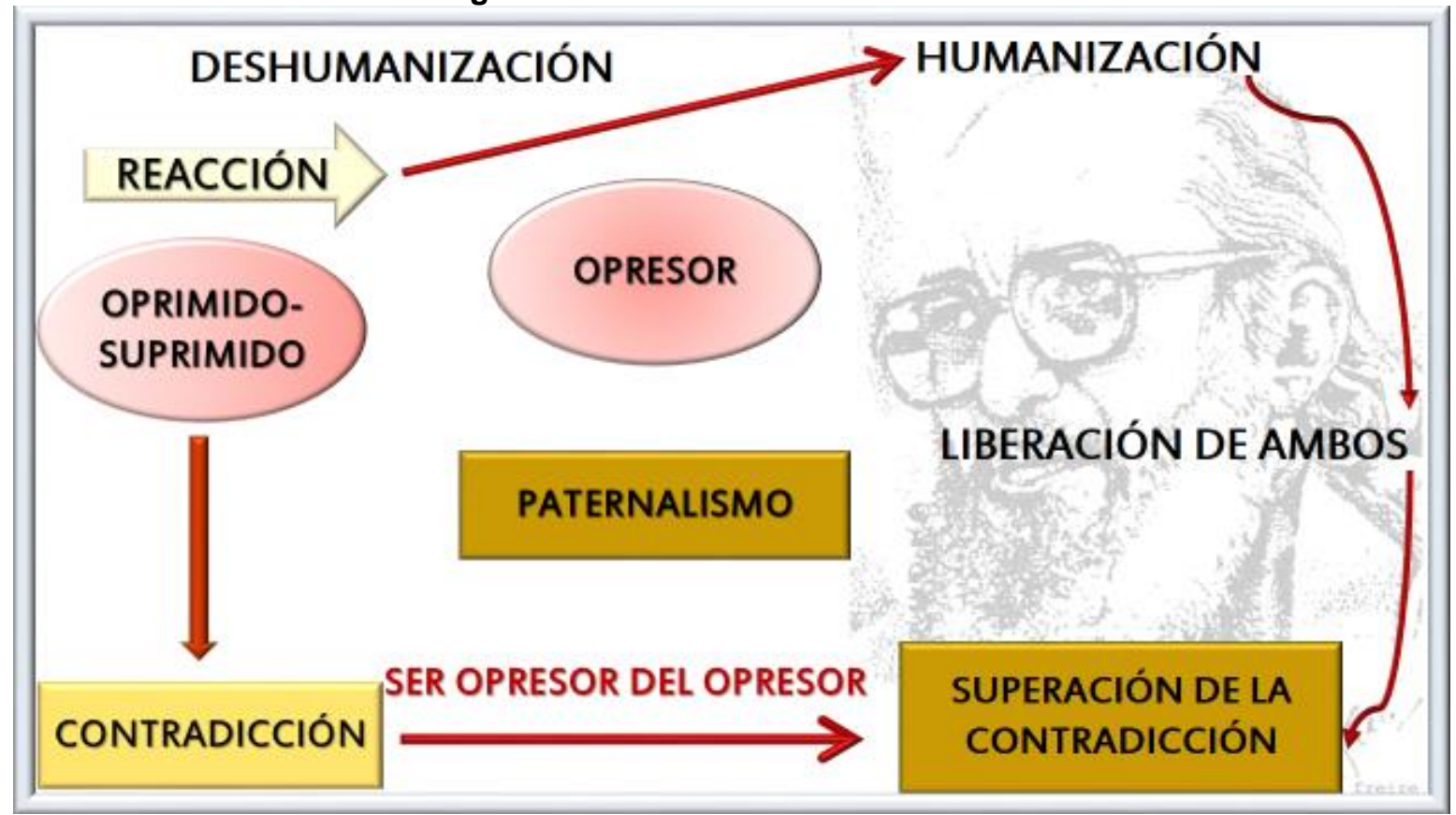

Fuente: construida para la investigación 2021.

Desde luego, con la deconstrucción rizomática podemos ir a reconstruir las líneas de salidas a las urgentes liberaciones actuales a la luz de Paulo Freire que nos da cátedra de liberación en tiempos de soslayación.

Rizoma reconstrucción: Paulo Freire un decolonial planetario adelantado en su tiempo: cátedra de liberación en tiempos de soslayación

Paulo Freire se adelanta a los oprimidos, ese adelanto va de la visión del ser humano que padeció en su piel, en su vida y comprende las luchas a emprenderse para la liberación; esta es un "es un parto doloroso. El hombre que nace de él es un hombre nuevo, hombre que solo es viable en la y por la superación de la contradicción opresores-oprimidos que, en última instancia, es la liberación de todos" (FREIRE, 1970, p. 45). Bajo ese entendimiento de las luchas por venir el parto se vuelve más doloroso cuando poderes politiqueros disfrazados de liberadores, de decoloniales, atentan contra el pueblo deseoso de liberación de la colonialidad impuesta continuación de colonialismo; y destruyen las ilusiones del pueblo con falsas liberaciones; y se demuele su economía, su educación; las luchas ya ganadas se pierden en desesperanza; con el poder adquisitivo del profesional ínfimamente inalcanzable. Como les describo ocurre tal cual en Venezuela. 
Ante tan tenebrosa realidad Paulo Freire da cátedra cuando recuerda que una educación liberadora es la salida para que el pueblo se empodere; para que la lucha sea bajo la criticidad; ya no sólo de aprender cognitivamente; no, esa educación empodera al ser de su función ciudadana; se trata de una educación portadora de

\begin{abstract}
Una pedagogía planetaria que se propone el surgimiento de una conciencia éticocrítica. Su acción educadora tiende, entonces, no solo a un mejoramiento cognitivo, aun de las víctimas sociales, o afectivo pulsional, sino a la producción de una conciencia ético-crítica que se origina en las mismas víctimas por ser los sujetos históricos privilegiados de su propia liberación. El acto pedagógico crítico se ejerce en el sujeto mismo y en su praxis de transformación: la liberación así es el «lugar» y el «propósito» de esta pedagogía" (DUSSEL, 2002, p. 439).
\end{abstract}

Nótese como pedagogía decolonial, liberación, decolonialidad planetaria se unen en un solo propósito: la liberación de la vida de las personas; una vida feliz. Ello es posible, y se debe llevar como praxis Freiriana; la ética aguarda a ser rescata en esa educación en el Sur, en la recivilización urgente emerge con gran fuerza la ética; que por conveniencia del sistema soslayador fue execrada de la educación en general: "no podemos asumirnos como sujetos de la búsqueda, de la decisión, de la ruptura, de la opción, como sujetos históricos, transformadores, a no ser que nos asumamos como sujetos éticos" (FREIRE, 1998, p.18). La eticidad es la reina de la responsabilidad social; de la política que dice que no sé es sino siendo en el otro; $y$ esté con nosotros.

El estar siendo con el otro es un tema por explorar en el Sur, es delicado cuidado el rescatar nuestra identidad; el llenarnos de lo que somos como seres históricos; "no somos sólo lo que heredamos ni únicamente lo que adquirimos, sino la relación dinámica y procesal de lo que heredamos y lo que adquirimos" (FREIRE, 1999, p.103); estas palabras de la obra Cartas a quien pretenda enseñar, son elocuentes actualmente en la obra Freiriana. Nos dicen de que debemos estar llenos los docentes; de que política debemos sentirnos, con que eticidad y antropolítica debemos restablecernos, y al son de que vamos a bailar en trascendental hecho de educar.

Descolonizar la educación es una tarea por explorar en los países soslayados, el adoctrinamiento curricular en Venezuela continua, pese a las reformas que se han venido realizando en las universidades tradicionales, "la verdadera cultura venezolana continúa encajonada, atiborrada tanto en los currículos como en la vida diaria, dando preferencia a culturas extranjeras y programas adoptados, alejados de la realidad contextual, de su importancia étnica, entre otros" (RODRÍGUEZ, 2017, p.431). En los últimos tiempos se 
intenta imponer formación de la cultura Cubana, que respetamos y admiramos; pero debemos estar consciente del respecto a la diversidad, y allí va el respeto por lo que somos como venezolanos portadores de excelencias; que no debemos olvidar que devenimos en formación de la cultura Occidental. En imposiciones el venezolano en las universidades no logra permease de su verdadera identidad; es adorador y consumidor de lo ajeno y allí hay una violencia epistémica claramente establecida; conveniente a los gobiernos de turno.

Ha habido últimamente un acercamiento en Venezuela a las comunidades al servicio comunitario de las universidades tradicionales, su currículo exige el servicio comunitario en los últimos semestres de los futuros profesionales. Pero ese hecho no es sustentable, es un saludo a la bandera; es un requisito que deja mucho que desear; es un paliativo; los saberes legos, del hábitat popular siguen arrinconados por las universidades en la esquina de los ineptos. Mientras que, en las universidades fundadas en este periodo de gobierno actual se preparan profesionales con nuevas carreras donde lo municipal reina; pero los vicios de calidad dejan mucho que desear.

Si es adecuado analizarnos como venezolanos; respondamos para el análisis sincero a la luz de la realidad actual: ¿contábamos con grupos decoloniales para apoyar la decolonialidad como proyecto de gobierno? ¿Se tomaron en cuenta los más preparados en dicha materia para gobernar? ¿Se confundió capitalismo con capital, decolonialidad significa ruina; o significa un desarrollo de vida inclusiva, digna y feliz? La educación nos ha venido preparando para la soslayación, para el capitalismo que abriga el sistema económico conveniente creando cinturones de miseria, eso vino ocurriendo en Venezuela. De ahí que, ahora sufrimos de las consecuencias de los errores de las imposiciones del gobierno de turno, de la descomposición de los ciudadanos y familias, además de un serio bloqueo; pues no hay que desmitificar el hecho que las grandes potencias siempre han esperado bloquear y saquear los recursos de esta inmensa nación. Cuna del hombre más importante de la historia, Simón Bolívar; luego del incomparable Jesucristo nuestro salvador.

Por otro lado, al respecto de la Educación Popular Freiriana, es por hoy una educación descolonizadora se compone en un instrumento de resistencia cultural que ayuda a las comunidades y a los actores educativos a comprender las necesidades de su país, y los instrumentos de soslayación en todo sentido que ha impuesto la mal llamada globalización. La Educación Popular ha estado ligada a procesos sociales y culturales 
liberadores desde su emergencia hace ya medio siglo; y tiene su meta en las masas oprimidas; la educación del pueblo venezolano debe recaer en su liberación onto epistemológica; una decolonialidad por hacer; una tarea por explorar que nos llevará a recobrar como la cuna del Libertador Simón Bolívar nuestra identidad de aguerridos que pasando por esta metamorfosis obligada nos recuperemos como seres libres; y reconstruyamos nuestra bella nación con conciencia libre de lo que propendemos; decantando los politiqueros que quieren ocupar cargos de soslayación para seguir la bandera de la opresión.

Se trata de, concientizarnos y llevar a la praxis, que "la educación como un acto de conocimiento, una toma de conciencia de la realidad, una lectura del mundo que precede a la lectura de la palabra" (FREIRE, 1983, p.51). Así, creemos en planos concretos que la educación por venir en el Sur; en Venezuela es la bandera que podemos portar y rescatar en el legado de Paulo Freire, de tal manera de hacer realidad que "la educación debe contribuir a construir sueños, a reinventar utopías y a sembrar esperanzas de cambio" (FREIRE, 2001, p.43). Si podemos transformar el mundo; si podemos ir a la recivilización de la humanidad; entendiendo que todos los problemas son de las civilizaciones; así "no hay palabra verdadera que no sea una unión inquebrantable entre acción y reflexión y por ende, que no sea praxis. De ahí que decir la palabra verdadera sea transformar el mundo" (FREIRE, 1970, p.99).

Paulo Freire a los 100 años de su vida hecha praxis de la liberación, nos recuerda los valores más esenciales a parte de la libertad que debemos recobrar como personas; es digno de buscar todo lo que esté a nuestro alcance para lograrlo; expresa el pedagogo, que debemos "rescatar valores que constituyen una ética universal de ser humano, la cuestión de la solidaridad, la amorosidad, la emocionalidad, la tolerancia, el respeto al otro en sus diferencias, el gusto por la alegría, la disposición al cambio” (Freire, 2002, p, 9). Por todo ello, es importante desmitificarnos del odio, terror, desamor, irrespeto, de la inhumana condición humana, de la exclusión como seres humanos. Todos debemos tener iguales oportunidades óptimas de realizarnos como persona; y en la convivencia debemos buscar tal realidad.

Paulo Freire da cátedra de liberación en tiempos de soslayación con su pedagogía de la esperanza: formas alternativas de pedagogía, que no sólo enfatizan las dimensiones interpretativas del conocer, sino que también ponen de relieve la idea de que cualquier idea 
liberadora del aprendizaje debe estar acompañada por relaciones pedagógicas marcadas por el diálogo- cuestionamiento- y la comunicación (FREIRE, 1970). Todo ello, lo estudia Henry Giroux en su obra Pedagogía y política de la esperanza. Teoría, cultura y enseñanza. Una antología crítica, donde enfatiza la teoría de la experiencia de Paulo Freiré que tiene sus raíces en una visión del lenguaje y la cultura que enlaza diálogo y significado a un proyecto social que enfatiza lo esencial de lo político (GIROUX, 1997).

En la pedagogía de la esperanza. Un reencuentro con la pedagogía del oprimido, Paulo Friere sigue confirmando que "los colonizados jamás podrían ser vistos y perfilados por los colonizadores como pueblos cultos, capaces, inteligentes, imaginativos, dignos de su libertad, productores" (FREIRE, 2002, p.185), en ello hay tomar urgencia que los procesos liberadores nunca son devenidos del poder soslayador que nos oprime, sigue sugiriendo en dicha obra el autor el rompimiento: una ruptura total con el colonialismo; lo que no indica que sea un proceso inmediato que vaya fuera de la luchas. Con ello, se revindica una vez más la diada: liberación-decolonialidad planetaria como preeminencia de la transmodernidad; donde Paulo Freire sigue dando cátedra en los estudios decoloniales del momento.

Desde luego, en esta reconstrucción donde vemos como Paulo Freire es un decolonial planetario adelantado en su tiempo y cátedra de liberación en tiempos de soslayación, no podemos dejar pasar por alto sus serios aportes en la liberación onto epistemológica del conocimiento a la luz de las construcciones de las subjetividades del sujeto y sus necesidades. Desmitifica Paulo Freire la imposición de conocimiento para soslayar a cambio de un conocimiento liberador como praxis de la búsqueda de soluciones a las necesidades más apremiantes de la vida de los oprimidos. Pero en especial, en tanto los saberes en las instituciones educativas para dicha liberación debemos indisciplinar las disciplinas (RODRÍGUEZ, 2018); a fin de que en la complejización de todos los saberes se consigan esencialidades para enseñar con mente, cuerpo y corazón liberando a los actores educativos.

De acuerdo a la anterior esto es más que un camino, es más bien una meseta escabrosa, pero posibles es aplicar la transdisciplinariedad en el pensamiento de Paulo Freire (SERNA, 2016). Se trata recobrar junto a los preceptos de la transdisciplinariedad la "pedagogía específica para ese tipo de educación a través de una vinculación entre los 
estudios, las experiencias vividas, el trabajo, la pedagogía y la política" (SERNA, 2016, p.214).

Esta forma de transdisciplinariedad con el pensamiento de Paulo Freire se trata de ir a recorriendo transversalmente la formación compleja a la luz de una pedagogía decolonial; que es altamente crítica y desprovista de dominios de elites. Transita Paulo Freire de la transdisciplinariedad a la transversalidad y viceversa; como teórico crítico en pos de una reconstrucción pedagógica Freire siempre consideraba directamente las preocupaciones señaladas por los estudiantes en constituyente de ciudadanía participativa y de integración: "siguiendo el pensamiento de Freire, la transdisciplinariedad se utiliza para investigar qué demandas direccionan al conocimiento para la resolución de problemas sociales con respecto a las preocupaciones más complejas" (SERNA, 2016, p.221).

En estos tiempos es menester siempre volver a Paulo Freire en la Educación y pedagogías decoloniales y transcomplejas, para recordar la gran emancipación por venir en su tarea; dicho pedagogo comparte elementos de esta "perspectiva en su concepción de la educación emancipadora, donde la pedagogía tiene sus raíces en las teorías y modos de aprendizaje, porque enseñar no es transferir conocimiento sino crear las posibilidades para su producción o construcción" (FREIRE, 1988, p.399). Esa posibilidad critica, decolonial, transdisciplinar y compleja debe tener la liberación del sujeto, de su vida y su realización plena como primera finalidad; de ahí que transcomplejidad sin pensarla en la decolonialidad planetaria; sino en la postmodernidad es un cuenco de mendigo: profundamente vacío.

Para finalizar estas pinceladas de Paulo Freire adelantado a sus tiempos no debemos olvidar que el gran pedagogo aporto a la Investigación Acción Participativa de manera crítica y en grandiosa misión de vida, padeciendo con los oprimidos; siendo el víctima de la opresión y el mejor agente de cambio y superación. Hoy donde los intereses se desvían de dicha forma de hacer investigación es importante recobrar la criticidad y complejidad Freiriana a fin de recobrar con valor por la vida y la solución de los problemas de padecimiento de las comunidades; no como paños de agua caliente; sino como verdadera transformación. Develar la realidad de dominación y alienación hoy, y el deber de preparar un gran campo de acción y planes liberadores para "anunciar otros caminos, convirtiéndose así en una herramienta emancipatoria" (FREIRE, 2000, p.74). 
Se recomienda así mismo, para la convergencia de los saberes matemáticos en las comunidades se dé un viraje, e insurgencia indisciplinar de la manera modernista de investigar; e ir a transmétodos, profundamente complejo, transdisciplinar y decolonial planetaria; por ejemplo la Investigación Acción Participativa Compleja (IAPC); ésta como transmétodo y así todos los transmétodos; ir más allá de los métodos colonizadores de la forma de investigar no elitizan las investigaciones en general y en la educación; no, por el contrario las aperturas; las engrandecen con un accionar han aportado a la comunidades por años; los sujetos verdaderamente en acciones humanas y respetando la condición humana siempre son los verdaderos protagonistas de la IAPC (RODRÍGUEZ, 2020e); ello es requerido ahora en los saberes soterrados; haciendo justicia en los saberes comunitarios execrados de la cientificidad; al mismo tiempo que se hace justicia a los seres humanos de donde devienen dichos saberes. Creemos que en ellos se encuentra el centro más incontaminado del saber.

Es de hacer notar que en las investigaciones de los saberes con la IAPC se pueden combinar transmétodos como IAPC (RODRíGUEZ, 2020c), puede accionarse combinada con otros transmétodos, dependiendo las necesidades de las transdisciplinas; por ejemplo con la deconstrucción como transmétodo, con la investigación transdisciplinar crítica, el análisis crítico del discurso o la hermenéutica comprensiva, ecosófica y diatópica que formando indagaciones transmetódicas van a complejizar aún más las investigaciones en los saberes.

Para ello, en esa justicia que reclama, en Venezuela se necesitan profesionales, docentes, comunidades, estudiantes dolientes; que si las políticas educativas reduccionistas aún en plena colonialidad se resisten estas convergencias y se unan en la búsqueda de verdaderas acciones libertarias del conocer y hacer de los saberesconocimientos. La educación tiene una gran carga de responsabilidad en ello (RODRÍGUEZ; PELETEIRO, 2020).

En lo que sigue con un gráfico se intenta mostrar este rizoma reconstructivo, esperando mejor comprensión de lo explicitado. 


\section{ENSIN@UFMS 2021}

ISSN 2525-7056

Figura 3. Paulo Freire un decolonial adelantado a su tiempo.

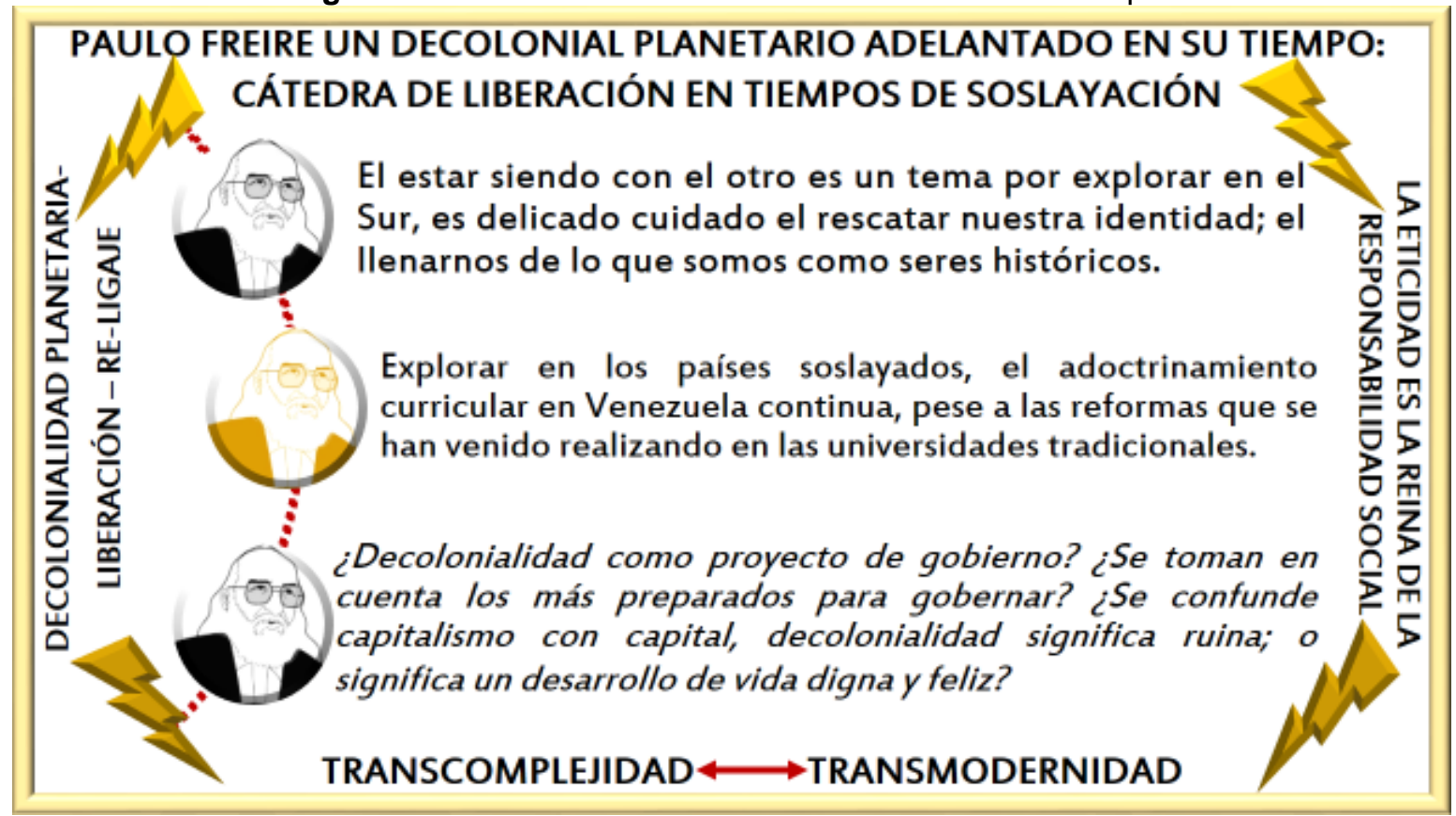

Fuente: construida para la investigación 2021.

En lo que sigue se culmina la indagación en aperturas freirianas en pleno centenario de su nacimiento.

\section{Rizoma conclusivo: el planeta necesita más del legado de Paulo Freire en la praxis}

La presente investigación transcompleja ha emergido como insurgencia con Paulo Freire; se trató de ir más allá de las indagaciones tradicionales; para inmiscuirnos en una indagación compleja y transdisciplinar; que con el transmétodo la deconstrucción rizomática transcompleja y se cumplió con el objetivo complejo de analizar la vida y obra de Paulo Freire como un decolonial planetario adelantado en su tiempo; que da actualmente cátedra de liberación en tiempo de soslayación.

Nótese la convergencia liberación Freiriana - decolonialidad planetaria que hemos venido develando; que no debe ser sorpresa en tanto Paulo Friere portador de la liberación de los oprimidos es primera tarea de la decolonialidad planetaria; esa liberación el pedagogo la plantea siempre desde la educación; con profunda fe en los educandos. Pero, podemos decir que Paulo Freire padeció las consecuencias de la colonialidad: pobreza, opresión, in-dignidad, soslayación y la falta de los fundamentes en general de la dignidad del ser humano. 
Al final como es un comienzo, tarea de la decolonialidad las palabras ya citadas de Paulo Freire deben volverse praxis siempre, en un amor por la humanidad; expresando el último pedagogo liberador de los oprimidos que los colonizados jamás podrían ser vistos y perfilados por los colonizadores como pueblos cultos, capaces, inteligentes, imaginativos, dignos de su libertad, productores, ya lo citamos en la deconstrucción realizada; no es menos para considerar que donde quiera que exista un ser humano considerado nadie, indigno desprotegido existe una muestra de la colonialidad en su máxima expresión. Pero ellos, los del ejercicio de poder, los colonizadores, también usan a nuestros propios hermanos en un poder de soslayación suave; que se ha venido usando en la educación; y desde allí muchos terminan diciéndote que no sirves para aprender; que tu genética no es la que se necesita para ser un gran profesional; e igual tu dignidad sigue abusada.

En cuanto a la investigación quisiera recobrar para culminar la intencionalidad de Paulo Freire ante la liberación de los oprimidos, se trata de la profunda fe en los educandos, la fe en su potencial aún en los que no podían leer las letras pero que tenían una necesidad profunda de liberación. Comprendía el pedagogo y podía leer las necesidades del mundo, las mismas que hace falta leer ante la intencionalidad soslayadora en el Sur especialmente ante políticas que como ayer cuando Freire lucho hoy hace falta la lucha con despertar el potencial del oprimido. Sabía Paulo Freire un ser humano cristiano que Dios no creo franjas de exclusión de seres humanos para ser desmitificados. No olvidemos el legado que dejo el pedagogo tras la invitación de la comunidad de iglesias y que sirvió en Angola y tantos otros países.

\section{Agradecimiento}

La línea titulada: transepistemologías de los conocimientos-saberes y transmetodologías transcomplejas lleva intrincada la subjetividad del sujeto investigador, esta vez la autora cristiana agradece a Dios mi proveedor de la sabiduría que siempre me da para su gloria eterna en esta tierra; "Y Dios me envió delante de vosotros para a preservaros un remanente en la tierra, y para daros vida por medio de una gran liberación" (BIBLIA, Génesis 45:7). Teniendo en cuenta siempre que "Tú eres mi refugio; me guardarás de la angustia; con cánticos de liberación me rodearás. Selah" (BIBLIA, Salmos 32:7). Y por ello, "porque sé que por vuestra oración y la suministración del Espíritu de Jesucristo, esto resultará en mi liberación" (BIBLIA, Filipenses, 1:19). Amén. 


\section{Referências}

GIROUX, H. Pedagogía y política de la esperanza. Teoría, cultura y enseñanza Una antología crítica. Buenos Aires - Madrid: Amorrortu editores, 1997.

GIROUX, H. Una vida de lucha, compromiso y esperanza. Cuadernos de pedagogía, v.265, p.42-45, 1998.

DUSSEL, E. Ética de la liberación en la edad de la globalización y de la exclusión. Madrid: Trotta, 2002.

LEMUS, J.; VELÁSQUEZ, A.; RODRÍGUEZ, M. Rasgadas las vestiduras en la Universidad de Oriente República Bolivariana de Venezuela. Revista Internacional de Pesquisa em Didática das Ciências e Matemática (Revln), Itapetininga, v. 1, e020018, p. 1-27, 2020.

FREIRE, P. Pedagogía del oprimido. Montevideo: Tierra Nueva, 1970.

FREIRE, P. Pedagogía de la autonomía. Segunda edición, México: Siglo XXI editores, S.A. de C.V., 1998

FREIRE, P. Cartas a quien pretenda enseñar. 5ª edición, México: Siglo XXI editores, S.A. de C.V., 1999

FREIRE, P. El acto de leer y el proceso de liberación. México: Siglo XXI Editores, 1983.

FREIRE, P. Pedagogía de la indignación. Cartas pedagógicas en un mundo revuelto. Sao Paulo: UNESP, 2000.

FREIRE, P. Pedagogía de la indignación. Madrid: Morata, 2001.

FREIRE, P. Pedagogía de la esperanza. Un recuentro con la pedagogía del oprimido. México: Siglo XXI Editores, 2002.

RODRÍGUEZ, M. E. Currículum, educación y cultura en la formación docente del siglo XXI desde la complejidad. Revista Educación y Humanismo, v.19, n.33, p.425-440, 2017. DOI: http://dx.doi.org/10.17081/eduhum.19.33.2654

RODRÍGUEZ, M. E. Estrategias Educativas Indisciplinares: Un Acercamiento a la Educación Matemática Transcompleja. En: Estrategias de enseñanza-aprendizaje: un acercamiento desde la práctica educativa. Editores: Instituto Universitario Anglo Español A. C., Red Durango de Investigadores Educativos A.C. p.74-97, 2018.

RODRÍGUEZ, M. E. Deconstrucción: un transmétodo rizomático transcomplejo en la transmodernidad. Sinergias educativas, v.4, n.2, p.1-13, 2019. DOI:

https://doi.org/10.31876/s.e.v4i1.35 (Fecha de consulta: 11/11/2020). 
RODRÍGUEZ, M. E. La hermenéutica comprensiva, ecosófica y diatópica: un transmétodo rizomático en la transmodernidad. Revista Perspectivas Metodológicas, v19, p.1-15, 2020a.

RODRÍGUEZ, M. E. La investigación transdisciplinar crítica: Un transmétodo rizomático en la transmodernidad. Revista Perspectivas Metodológicas, v. 21, e3165, 1-10, $2020 \mathrm{~b}$.

RODRíGUEZ, M. E. La Investigación Acción Participativa Compleja como transmétodo rizomático transcomplejo en la transmodernidad. Revista Internacional de Formación de Professores (RIFP), Itapetininga, v. 5, e020026, p. 1-27, 2020c.

RODRÍGUEZ, M. E.; PELETEIRO, I. Antropolítica en Venezuela: un cuenco de mendigo, más aún en tiempos de pandemia 2020. SUMMA. Revista disciplinaria en ciencias económicas y sociales, 2(Especial), p.v.117-139, 2020. DOI:

www.doi.org/10.47666/summa.2.esp.09

SERNA, E. La transdisciplinariedad en el pensamiento de Paulo Freire. Revista de Humanidades, n.33, p.213-243, 2016.

\section{NOTAS}

\section{IDENTIFICAÇÃO DE AUTORIA}

Milagros Elena Rodríguez. PhD en Ciencias de la Educación. Universidad de Oriente, Núcleo de Sucre, Departamento de Matemática, Cumaná, Sucre, Venezuela.

E-mail: melenamate@hotmail.com

(i) http://orcid.org/0000-0002-0311-1705

\section{AGRADECIMENTOS}

Não se aplica.

\section{FINANCIAMENTO}

Não se aplica.

\section{CONSENTIMENTO DE USO DE IMAGEM}

Não se aplica.

\section{APROVAÇÃO DE COMITÊ DE ÉTICA EM PESQUISA}

Não se aplica.

\section{LICENÇA DE USO}

Autores mantêm os direitos autorais e concedem à revista ENSIN@ UFMS - ISSN 2525-7056 o direito de primeira publicação, com o trabalho simultaneamente licenciado sob a Licença Creative Commons Attribution (CC BY-NC-SA 4.0), que permite compartilhar e adaptar o trabalho, para fins não comerciais, reconhecendo a autoria do texto e publicação inicial neste periódico, desde que adotem a mesma licença, compartilhar igual.

\section{EDITORES}

Patricia Helena Mirandola Garcia, Eugenia Brunilda Opazo Uribe, Gerson dos Santos Farias.

\section{HISTÓRICO}

Recebido em: 26/01/2021 - Aprovado em: 08/11/2021 - Publicado em: 06/12/2021. 


\section{COMO CITAR}

RODRIGUEZ, M. E. Paulo Freire hoy, ante la Intencionalidad Decolonial del Pensamiento del Sur. Revista ENSIN@ UFMS, Três Lagoas, v. 2, n. 6, p. 198-220. 2021. 